\title{
The structure of the "lived-experience": analysis of reports from women with systemic lupus erythematosus
}

\author{
Bruna Paes de Barros ${ }^{1}$, Camila Bernardes de Souza², Gianna Mastroianni Kirsztajn ${ }^{1}$ \\ 1. Glomerulopathy Section, Federal University of Sao Paulo, Brazi. 2. Psychology Group, Federal University of Sao Paulo, \\ Brazi
}

Correspondence: Bruna Paes de Barros, Gianna Mastroianni Kirsztajn. Address: R. Botucatu, 740 2ำ andar-Disciplina de Nefrologia (UNIFESP), Sao Paulo/SP, CEP 04023-900, Brazil. E-mail: gianna@nefro.epm.br

Received: December 4, 2011

Accepted: February 13, $2012 \quad$ Published: August 1, 2012

DOI : $10.5430 /$ jnep.v2n3p120

URL: http://dx.doi.org/10.5430/jnep.v2n3p120

\section{Abstract}

Objective: To investigate how systemic lupus erythematosus (SLE) has changed the lives of affected women and their reports on how this condition has affected them.

Method: Interviews were performed in accordance with the qualitative study method of Amatuzzi and the answers were recorded.

Results: Patients have reported that it is difficult to deal with this disease, their lives have changed, in particular their body image, as a result of treatment side effects. The lack of familiarity of other people with the disease brings several consequences such as discrimination, difficulties in obtaining a job and changes in their interpersonal relationships. Treatment compliance is often maintained due to the fear related to the unpredictable disease course. The imminence of a possible lupus flare can cause anxiety and fear, imposing limits to their lives. Since the disease has no regular course, it is perceived as a threat to their existence and, consequently, they feel persecuted by a death threat.

Conclusions: Psychological manifestations related to the disease based on patients' reports are discussed, together with the importance of multi-professional assistance, highlighting the role of the mental health professional as an essential tool to reach an overall understanding and adequate treatment for patients with SLE.

\section{Key words}

Anxiety, Compliance, Lupus flare, Mental health, Systemic lupus erythematosus

\section{I ntroduction}

In the psychological context, several alterations have been observed in patients with systemic lupus erythematosus (SLE) such as psychoses, mood disturbances, cerebral organic syndromes, cognitive alterations, reactions to drugs (particularly corticosteroids), functional dysfunctions, circadian bio-rhythm changes, and some dysfunctions of the autonomous nervous system. It is well-known that adjustment reactions also occur ${ }^{[1-3]}$. 
Depression is one of the most frequent psychiatric manifestations in patients with SLE, which symptoms are: feeling of failure , loss of social interests, feeling of punishment,, suicidal thoughts, dissatisfaction, lack of will and determination, and sadness ${ }^{[4]}$. In this context, psychologists play an important role in the follow-up of patients with SLE, in particular those with lupus nephritis, as the course of this disease not rarely leads to chronic renal failure and even to end-stage renal disease, favoring psychological disturbances, and sometimes death ${ }^{[1,3,5-7]}$.

Considering that psychological factors can have variable impact on the course of SLE and vice-versa, this research intends to provide an overview on the structure and changes observed by patients in their lives until the moment of this study.

\section{Design}

\subsection{Participants}

A convenience sample of twelve patients with SLE followed in the Glomerulopathy outpatient clinic of the Federal University of Sao Paulo (UNIFESP) were included in the study. This clinic is a national reference center for SLE, especially lupus nephritis, located in Sao Paulo, the largest city of the country, capital of the state of Sao Paulo, southeastern Brazil.

The inclusion criteria were: 15-40 years-old females and diagnosis of SLE in accordance with the ARA (American Rheumatism Association) classification ${ }^{[8]}$. The exclusion of men and other age group was based on the significantly higher incidence of the disease among women of child bearing age ${ }^{[9]}$.

\subsection{I nstrument}

A semi structured clinical interview, as proposed by Bleger ${ }^{[10]}$, was initiated with the following question "How is it for you to have lupus?”

\subsection{Procedures}

The patient was invited by the psychologist of the research team to participate in the research, when attending their routine medical visits. Fifteen patients were invited, and 12 accepted to participate. They received previously an explanatory information (so that they knew what they might be consenting to do), and they had also time to discuss it with a relative or friend. The project was approved by the Ethics Committee of the university and the patients signed an informed consent form. After this, the interview was carried out individually by the psychologist.

The interviews were recorded in audio tapes, so that there was no loss of content of the answers. Then, they were transcribed as soon as possible, respecting the way patients expressed their opinions.

The 'meanings' that the investigators could detect in the patients' reports were based on the totality of experiences lived by each individual. This is the approach proposed by Martins and Bicudo ${ }^{[11]}$. A phenomenological existential approach was used in the analysis of reports.

The written interviews were read and categorized, as described in the method of analysis of four moments, proposed by Amatuzzi ${ }^{[12]}$ and Martins and Bicudo ${ }^{[11]}$. Shortly, this method corresponds to: 1) a first reading of the interview, without searching for any interpretation of what is written or without any attempt to identify any attribute or element in the text. This reading was aimed at obtaining a general end for all the affirmations; 2) a return to the beginning of the reading, and then reading the text again, as many times as necessary, with the aim of discriminating units of meaning inside a psychological perspective, by focusing on the phenomenon that is being searched; 3) after establishing the 'units of meaning', a new reading, is performed and the professional expresses directly the psychological 'insight' contained in the 
text; 4) then, a new evaluation of the text is performed in order to synthesize all the 'units of meaning', now transformed into a consistent proposal of the individual's experiences. This is commonly called structure of the experience.

All interviews were compared in order to find common subjects and to establish categories, according to the meaning attributed, leading to the categories described in the 'Results', in a temporal manner, i.e., from the first signs and symptoms up to the moment of the study interview. The average duration of interviews was 11 minutes, ranging from 4 to 30 minutes. The reports were grouped into categories (and shown in italic along this text) and some patients' answers are shown, where $\mathrm{P} 1$ is patient 1, P2, patient 2 and so on.

\section{Results}

As previously explained, after reading the transcriptions of the interviews, the answers were classified by the authors into the following categories that represent the psychological structure lived by patients with SLE. The quotes were given as examples to support the arguments and expressed views of other participants, and not only those indicated by their identification number.

The difficulties and suffering of the trajectory lived since the first symptoms by the time of diagnosis are described by the patients:

P2: "I was two weeks in the ICU (intensive care unit) and suddenly I was well".

Concomitantly to the diagnosis, many doubts related to the disease appeared leading to the perception of the lack of familiarity with their own disease:

P6: "I was in doubt whether it was cancer".

And to the perception of the lack of familiarity with the disease by the others:

P1: "Because there are so many people who do not know what it is. They do not understand what it is".

P10: "They think that you have a contagious disease".

Giving rise to feelings of rejection:

P5: "We feel rejected, you know".

Modifying their interpersonal relationships:

P10: "People open their eyes wide, they do not know what it is... It is no use to speak about lupus to an ignorant person...".

Modifying their professional perspectives:

P1: "There are also people who look for a job, or have to go through a medical test, and they are not approved... ".

Modifying their family relationships:

P4: "My family was desperate".

Beyond the changes in their relationships, women perceive important changes in their own body image: 
P4: "I am always swelled, with painful joints, or marks on the skin. When I look at myself in the mirror, I realize that I am different, I feel sad, and I do not like to feel that way".

Then, they talk about the need to maintain a rigorous adhesion to the medical treatment:

P5: "To do what the doctors say".

P12: "You have to take the medication every day; you cannot forget to take it".

In part of this population, the adhesion to the treatment is supported by the feeling of uncertainty and unpredictability of the disease course:

P1: "It is a disease that... catches you all of a sudden, you know".

P12: "If you forget to take, something can happen, then... you know".

Uncertainty about the future is many times evoked by memories related to known cases of poor SLE prognosis:

P2: "You even hear people saying that they know somebody who passed away because of lupus".

P12: "My sister came to death (due to SLE)".

Regarding the uncertainties of the disease course, patients establish ways of helping them to face the disease:

P8: "So you have to look forward to live the best way you can and carry on... ".

These changes in the way of being have also consequences on medical treatment:

P4: "The important is that you have to try to do all things right" (the prescribed treatment).

On their personal support networks:

P1: “...You need to have family support”.

On their religious beliefs:

P1: "I think that spiritual aspects contribute a lot".

P5: "I asked God not to have to do hemodialysis".

They think that the lack of information could explain why people reject them:

P11: "They should explain what it is. There is lack of information...”.

They feel the limits given by their own disease and the therapeutical treatment:

P1: "You cannot be in the sun, you know".

P4: "The fact that you have to monthly come here in the hospital is already a boring thing".

When they evaluate what SLE has made with their lives, they realize how difficult it is to live with this disease: 
P2: "It is not easy".

P6: "Frightful".

E10: "It is kind of boring".

Therefore, associated to this condition, they perceive life changes:

P1: "My life has changed so much".

P7: "It has changed entirely".

The change is felt as something hard to deal with, as a problem:

P5: "It is very complicated".

P8: "Having this problem".

At the end, they were grateful for participating in this research and talking about their lives.

\section{Discussion}

Psychiatric and neurological disorders, as well as epidemiological, clinical and laboratory data of patients with SLE have been extensively studied; however, there are few studies addressing the psychological aspects taking into account the perspective of patients, their support network throughout the disease course. Nevertheless recently studies with similar methodology and results have been conducted in Brazil and other countries ${ }^{[13-15]}$.

Not infrequently, psychological aspects are neglected in this population, especially due to the lack of studies in the area. Still, it is interesting to observe that both experienced rheumatologists and patients themselves often associate the worsening or the time of SLE diagnosis with a situation of stress ${ }^{[16]}$. In the Brazilian consensus of SLE, rheumatologists recommend, among other measures, psychological support for patients in order to give some optimism and motivation for treatment and encourage life projects ${ }^{[17]}$. Other authors believe that patients that have received multidisciplinary care are more likely to show better outcome, such as Bastos and Mastroianni-Kirsztajn ${ }^{[18]}$.

The work of multidisciplinary teams, including the presence of psychologist in the monitoring of these patients has been discussed by the scientific community, since the development of SLE frequently leads to chronic kidney disease, including end-stage renal disease and sometimes death ${ }^{[1,4,10,19,20]}$. Undoubtedly, the psychologist can help to assist more effectively the patient suffering from this disease, working with patient, family and health staff.

The psychological repercussions are inseparable from biological, social and spiritual aspects with regard to patients with SLE, so that the onset of the disease for most of these patients was marked by traumatic experiences denoting difficulties and suffering due to the trajectory experienced since the first symptoms.

By the time of diagnosis, the patients have many doubts, and frequently believe to have other serious diseases, leading to the perception of their own unfamiliarity with SLE. The crisis unchained by their initial experiences can cause emotional distress. Thus, patients perceive that they need to reorganize themselves to face the new condition.

The perception of the lack of familiarity of others with the disease causes a disturbance in their relationships, and especially when they need help, such unfamiliarity is felt by patients as rejection. Being ill can mean feeling abandoned, 
without protection, anxious, even when they are not aware of their own anxiety ${ }^{[21]}$. Being ill means to feel things in a different way, to see in a different way, to live in a partially or totally different world. And yet, with the disease, the dynamics of the relationship between individuals and themselves or with the world are disrupted ${ }^{[22]}$. Changes in this dynamics were observed in the present study in the interpersonal and family context, body image and life perspectives.

The family, as well as the patient, can undergo several emotional states such as: fear, anxiety, anguish, mobilization of defense mechanisms (negation, rationalization and fantasies are the most frequent), but in this case, mobilization has the intention of overcoming the crisis ${ }^{[22]}$.

Disease stigmas and side effects of medications are usually perceived by the patients when there are changes in their body image, and this can affect their social and sexual habits and contribute to low self-esteem. Through their body, individuals have conscience of the world ${ }^{[23]}$. Having a chronic disease makes patients to experience the loss of a healthy and active body. For many, non-adequate body functioning leads to loss of autonomy ${ }^{[22]}$.

For a long time, patients with SLE have been aware of the necessity to maintain rigorous adhesion to the medical treatment, since the lack of compliance might worsen their clinical condition. It is evident in their reports that adhesion to treatment is partly maintained by uncertainties and unpredictability of the disease. In this way, anxiety can have all sorts of 'faces' and intensities, since it is a basic human reaction to a danger that threatens existence or values. Anxiety is the feeling of being 'attached' or 'oppressed', blunting the patient's perceptions ${ }^{[23]}$. The disease as a threat to the existence of these patients generates anxiety and concurrently death threat, which is the most common symptom of anxiety ${ }^{[24]}$. Beyond having a chronic disease, our patients have other reasons to be anxious, such as the imminence of worsening of their general health state by a predictable reactivation of SLE, above all by renal involvement, which enables the real increase in morbidity and mortality in cases of SLE ${ }^{[5]}$.

They also have to undergo a series of health procedures that demand time and patience, such as making frequent exams, coming to visits and following a complex treatment with a non negligible number of side effects. Thus, their future is uncertain, threatened by the imminence of a lupus flare and the main sign of a crisis are experiencing an empty future ${ }^{[25]}$. In addition, subjects that have suffered from a serious physical disease can have anxiety, the fear of not feeling well ${ }^{[26]}$.

Thus, it is possible to observe the effort of patients to maintain the routine they had before the onset of the disease. The preservation of their routine is reached by new adaptations in the way of being and leading with their treatments, support networks and beliefs. It has been observed from interviews the importance attributed to religion as a tool to face the disease; and psychologically, religion can be considered as a way of relating with their own spirituality ${ }^{[24]}$.

They suffer from not knowing how to face the new situation of living with a complex disease like SLE, and how to act, since their strategies do not fit the new circumstances. In the lives of these women, a chronic disease has never been foreseen; thus, SLE has invaded their world and interrupted the continuity of life process, i.e., it has caused a crisis. This is potentially a source of suffering ${ }^{[27]}$. It is very difficult to deal with the disease; in addition, life with SLE implies to face a series of obstacles and changes, to have a serious problem as reported by our patients.

Regarding the limits imposed by the disease and therapeutic treatments, restrictions reinforce their dependence, which for patients; it is an aggression, because they perceive themselves under the domain of the hospital structure, and under the power of health professionals who, many times, take away their autonomy and decision-making capacity.

Health professionals should be fully involved in the care of patients with SLE, as the psycho affective and social components of the treatment can be seen as advantages in the therapeutic process ${ }^{[28]}$. In addition, some authors believe that multi-professional health care is extremely relevant in this condition, including attention to bio-psycho-social needs of these patients during follow-up, as the disease changes their life plans, affects their career, family life, life style, productivity and income ${ }^{[26]}$. It is interesting to notice that at the end of the interview, many patients were thankful for 
having been listened to. For them, participating on this research, more than telling how it is to have SLE, was a moment to reflect and to speak about themselves, together with somebody who was listening to them.

Certainly, health professionals who deal with these patients should want to listen to them, especially because they are 'perpetual' patients, due to their need of regular and frequent follow-up, and to the demands of the disease. It has been observed that, in the reports of their more significant experiences, patients review the trajectory of their lives since the first signals of the disease, the profound life changes, their new way to view the past and the feelings related to the disease. The future gained prominence due to the uncertainties related to the eventual progression of the disease. Thus, in the structure of the 'lived-experience', significant experiences have allowed characterizing self-perceptions about doubts, rejections, unreliabilities, uncertainties, memories, frustrations, submission, and dissatisfaction.

The aspects that are frequently shown in their speech include the perception of changes in their body image, the need to maintain rigorous adhesion to the medical treatment, as well as the 'ways of being' to deal with the disease. They also report that it is necessary to inform people about SLE, mainly as a way to minimize the feelings of rejection caused by the lack of familiarity with the disease observed among patients, their relatives and even among health professionals.

\section{References}

[1] Shortall E, Isenberg D, Newman SP. Factors associated with mood and mood disorders in SLE. Lupus. 1995; 4(4): $272-279$. PMid:8528223 http://dx.doi.org/10.1177/096120339500400407

[2] Hugo FJ, Halland AM, Spangenberg JJ, et al. DSM-III-R classification of psychiatric symptoms in systemic lupus erythematosus. Psychosomatics. 1996; 37(3): 262-269. http://dx.doi.org/10.1016/S0033-3182(96)71565-7

[3] Hochberg MC. The epidemiology of systemic lupus erythematosus. In: Wallace DJ, Hahn BH, eds. Dubois' Lupus Erythematosus. Baltimore: Williams \& Wilkins; 1997.

[4] Shapiro HS. Depression in Lupus [Internet]. 2001. Available from: http://www.hamline.edu/lupus/articles/Depression_in_Lupus.html. Accessed Mar 7, 2001.

[5] Cruz BA. Atualização em Reumatologia: Nefrite Lúpica. Rev Bras Reumatol. 2008; 48(3): 173-177. http://dx.doi.org/10.1590/S0482-50042008000300007

[6] Melo AKG, Avelar AB, Maegawa FKM, Souza BDB. Avaliação de 100 pacientes com nefrite lúpica acompanhados por dois anos. Rev Bras Reumatol. 2009; 49(1): 8-19. http://dx.doi.org/10.1590/S0482-50042009000100002

[7] Hunter MG, Hurwitz S, Bellamy CO, Duffield JS. Quantitative morphometry of lupus nephritis: the significance of collagen, tubular space, and inflammatory infiltrate. Kidney Int. 2005; 67(1): 94-102. PMid:15610232 http://dx.doi.org/10.1111/j.1523-1755.2005.00059.x

[8] Tan EM, Cohen AS, Fries JF, et al. The 1982 revised criteria for the classification of systemic lupus erythematosus. Arthritis Rheum. 1982; 25(11): 1271-1277. http://dx.doi.org/10.1002/art.1780251101

[9] Shapiro HS. Psychopathology in the patient with Lupus. In: Wallace DJ, Hahn BH, eds. Dubois' Lupus Erythematosus. Baltimore: Williams \& Wilkins; 1997.

[10] Bleger J. Temas de Psicología - Entrevista y grupos. Buenos Aires: Ediciones Nueva Visión; 1979.

[11] Martins J, Bicudo MAV. A Pesquisa Qualitativa em Psicologia. São Paulo: Moraes; 1994.

[12] Amatuzzi MM. Apontamentos acerca da pesquisa fenomenológica. Estudos de Psicologia - Rev IPPUCCAMP. $1996 ; 13(1)$ : 5-10.

[13] Araújo AD, Traverso-Yépez MA. Expressões e sentidos do lúpus eritematoso sistêmico (LES). Estudos de Psicologia. 2007; 12(2): 119-127.

[14] Robinson D Jr., Aguilar D, Schoenwetter M, et al. Impact of systemic lupus erythematosus on health, family, and work: the patient perspective. Arthritis Care Res (Hoboken). 2010; 62(2): 266-273. http://dx.doi.org/10.1002/acr.20077

[15] McElhone K, Abbott J, Gray J, Williams A, Teh LS. Patient perspective of systemic lupus erythematosus in relation to health-related quality of life concepts: a qualitative study. Lupus. 2010; 19(14): 1640-1647. PMid:20709719 http://dx.doi.org/10.1177/0961203310378668

[16] Nery FG, Borba EF, Lotufo Neto F. Influência do estresse psicossocial no lupus eritematoso sistêmico. Rev Bras Reumatol. 2004; 44(5): 355-361. http://dx.doi.org/10.1590/S0482-50042004000500007

[17] SBRE. Consenso de lúpus eritematoso sistêmico. 2009. Available from: http://www.cerir.org.br/pdf/Consenso_Lupus.pdf Accessed November, 2011. 
[18] Bastos MG, Mastroianni-Kirsztajn G. Doença renal crônica: importância do diagnóstico precoce, encaminhamento imediato e abordagem interdisciplinar estruturada para melhora do desfecho em pacientes ainda não submetidos à diálise. J Bras Nefrol. 2011; 33(1): 93-108. PMid:21541469 http://dx.doi.org/10.1590/S0101-28002011000100013

[19] Resende C, Sanga NMS, Paschoalotti ALH, Zerbini CAF. Manifestações neurológicas no lúpus eritematoso sistêmico. Rev Paul Med. 1987; 105: 289-293.

[20] Kamijo Y, Kaneko Y, Ichikawa T, et al. A case of nephrotic syndrome due to lupus nephritis which was controlled with low-density lipoprotein apheresis. Ther Apher. 2002; 6(6): 459-462. http://dx.doi.org/10.1046/j.1526-0968.2002.00458.x

[21] Perestrello D. A medicina da pessoa. Abordagem da pessoa e seu adoecer em clínica médica. Rio de Janeiro: Atheneu; 1974.

[22] Santos CT, Sebastiani RW. Acompanhamento psicológico à pessoa portadora de doença crônica. In: Angerami-Camon VA, ed. E a Psicologia entrou no hospital... São Paulo: Editora Pioneira; 1996.

[23] Merleau-Ponty M. Phénoménologie de la perception. Paris: Éditions Gallimard; 1999.

[24] May R. Man's search for himself. New York: WW Norton \& Company Inc; 1953.

[25] Moffatt A. Terapia de crisis. Buenos Aires: Editorial Búsqueda; 1982.

[26] May R. The meaning of anxiety. New York: WW Norton \& Company Inc; 1977.

[27] Gameiro MH. Sofrimento na doença. Coimbra: Editora Quarteto; 2001.

[28] Wallace DJ. Principles of therapy and local measures. In: Wallace DJ, Hahn BH, eds. Dubois' Lupus Erythematosus. Baltimore: Williams \& Wilkins; 1997. 